\title{
Cultural Factors Influencing Functional Gastrointestinal Disorders in the East
}

\author{
Kee-Huat Chuah and Sanjiv Mahadeva* \\ Division of Gastroenterology, Department of Medicine, Faculty of Medicine, University of Malaya, Kuala Lumpur, Malaysia
}

Culture forms an integral aspect of environmental factors which influences disease presentation and clinical outcomes in functional gastrointestinal disorders (FGIDs). In this review, the role of culture in FGIDs in the East is briefly explored with regards to symptom presentation and diagnostic issues, lifestyle and cultural habits, epidemiology, and healthcare seeking behavior. In both functional dyspepsia and irritable bowel syndrome, symptom presentation and disease sub-typing in Asians are known to differ from their Western counterparts, possibly relating to cultural dietary practices and from cultural perception of symptoms. Dietary patterns, together with defecating practices are explored as factors contributing to a lower prevalence of constipation in the East. An urban-rural difference in the prevalence of FGIDs in Asia is attributed to a change in dietary patterns in rapidly developing urban communities, together with an increased level of psychological morbidity. Lastly, cultural attitudes towards traditional/local remedies, variation in healthcare systems, anxiety regarding organic disease, and religious practices have been shown to influence healthcare seeking behavior among FGID patients in the East.

(J Neurogastroenterol Motil 2018;24:536-543)

Key Words

Asia; Culture; Dyspepsia; Epidemiology; Irritable bowel syndrome

\section{Introduction}

Functional gastrointestinal disorders (FGIDs) are disorders with chronic or recurrent symptoms attributable to the gastrointestinal (GI) tract in the absence of organic disease that can be identified by routine investigations. Diagnosis of FGIDs are mainly based on patient's symptoms interpretation and reporting. Functional dyspepsia (FD) and irritable bowel syndrome (IBS) are among the most established FGIDs. They are also one of the most common gastroenterology conditions encountered in the community, as well as in gastroenterology and specialist clinics. Yet these conditions are not well understood and constantly pose treatment difficulties to cli- nicians. Although FGIDs do not lead to an increase in mortality, ${ }^{1,2}$ they cause significant morbidity, in terms of affecting quality of life and increasing healthcare utilization. ${ }^{3-5}$

FGIDs are known to result from a complex interaction between biological, psychological and social factors. ${ }^{6}$ In the biopsychosocial model of IBS, developed by a multi-disciplinary expert committee in an attempt to understand the condition better, genetic and environmental factors influence both the brain and the gut, which in turn interact bidirectionally via the autonomic nervous system and the hypothalamus-pituitary-adrenal axis. Within this model, culture forms an integral component of the environmental factors. ${ }^{6}$ Culture is defined as the values, beliefs, norms, and practices of a group of people which guide thinking, decisions, and actions in a patterned

Received: April 6, 2018 Revised: July 16, 2018 Accepted: July 21, 2018

(c) This is an Open Access article distributed under the terms of the Creative Commons Attribution Non-Commercial License (http://creativecommons. org/licenses/by-nc/4.0) which permits unrestricted non-commercial use, distribution, and reproduction in any medium, provided the original work is properly cited.

*Correspondence: Sanjiv Mahadeva, MD Division of Gastroenterology, Department of Medicine, Faculty of Medicine, University of Malaya, Kuala Lumpur 50603, Malaysia Tel:+60-3-79492299, Fax: +60-3-79492693, E-mail: sanjiv@ummc.edu.my 
way. $^{7}$

In 2 recent review articles on $\mathrm{FD}^{4}$ and $\mathrm{IBS}^{8}$ various differences in clinical presentation and impact of these conditions were observed between the East and the West. In these reviews, "East" included countries from Asia, while Western countries included countries from Europe, North America, and Australia, mainly due to similarities in culture and diet. ${ }^{9}$ Whilst some of these clinical variations may have been due to epidemiological differences between Asian and Western populations, it is likely that differences in culture may have had a role as well. The influence of culture on various aspects of the diagnosis, treatment and health outcomes of FGIDs in Western studies have recently been reported. ${ }^{7}$ However, little is known about the impact of culture on FGIDs in the East/Asia. This review attempts to highlight the role of culture in FGIDs in the East with regards to: symptom presentation and diagnostic issues, lifestyle and cultural habits, epidemiology, and healthcare seeking behavior.

\section{Symptom Presentation and Diagnostic Issues}

FD based on the the Rome III and IV criteria is subdivided into epigastric pain syndrome (EPS) and post prandial distress syndrome (PDS). ${ }^{10}$ PDS involves patients with early satiety, and postprandial fullness and is considered to be meal related. EPS includes patient presenting with epigastric pain or burning and is considered to be non-meal related. A recent review article has indicated that the proportion of patients with PDS and EPS appears to differ between the East (Asia) and the West. ${ }^{4}$ Studies in Korea and Japan using the Rome III criteria reported that PDS was present in $69.9 \%$ and $81.3 \%$ of patients with dyspepsia, whereas studies in the United States reported that only $50.0 \%$ of their patients with dyspepsia presented with bloating. ${ }^{11}$ Recently, two large endoscopy-based community studies in Taiwan and Canada, using similar diagnostic criteria for FD, were published. In the Taiwanese study, $71.9 \%$ of 491 patients with FD had a PDS sub-type and $34.4 \%$ had an overlap of EPS and PDS, ${ }^{12}$ while 347 (40.8\%) had PDS alone, and 351 (41.2\%) met the criteria for both EPS and PDS in the Canadian study. ${ }^{13}$ In a cross sectional study comparing Malaysian and British age-matched adults who were referred for endoscopy, investigators reported that Malaysian patients with dyspepsia had a significantly higher frequency of belching (70.0\% Malaysian vs 30.0\% British, $P<0.001)$ and early satiety/bloating (52.0\% Malaysian vs $32.0 \%$ British, $P<0.001)$ compared with their British counterparts. ${ }^{14}$

Among the various possibilities as to why PDS or dysmotility- type FD is more common in Asians compared to Westerners, lies the role of Helicobacter pylori infection. H. pylori associated chronic gastritis is thought to cause FD symptoms by altering gastroduodenal motility and sensitivity, including influencing the production of GI hormones and neurotransmitters somatostatin, gastrin, and ghrelin. Furthermore, H. pylori is postulated to damage the ghrelin producing gastric X/A like cells. As a result, ghrelin secretion decreases which could delay gastric emptying, resulting in postprandial fullness. ${ }^{15}$ The fact that the prevalence of $H$. pylori is higher in Asia and that infected Asian adults with FD tend to have a greater symptom response with eradication therapy compared to Westerners ${ }^{15}$ supports its role for the difference in FD sub-types between the East and West (Table 1).

A major factor for the difference in $H$. pylori prevalence between the East and the West has been attributed to variations in sanitation and socioeconomic status. ${ }^{16}$ However, certain cultural practices have been suggested as contributing towards a greater prevalence of $H$. pylori in East Asia. A study of Asian immigrants to Australia had previously identified that the use of chopsticks was an independent predictor of $H$. pylori presence. ${ }^{17}$ This study additionally demonstrated a difference in $H$. pylori prevalence between ethnic Chinese migrants from Malaysia/Singapore vs those from mainland China, supporting the notion that different cultural practices influenced the transmission of $H$. pylori.

Globally, the diagnosis of IBS has been based on the "Rome Criteria" which includes recurrent abdominal pain (Rome IV) or discomfort (Rome I-III), related to defecation, associated with a change in frequency or consistency of stool. ${ }^{10}$ However, the recent Asian consensus on IBS reported that "abdominal pain" was not commonly identified in Asians with IBS, while bloating and discomfort were more common and even defined bloating as a key

Table 1. Differences in Functional Dyspepsia Prevalence, Functional Dyspepsia Sub-types, H. pylori Prevalence and Symptom Response Following H. pylori Eradication Between the East and the West

\begin{tabular}{lrr}
\hline & \multicolumn{1}{c}{ West } & \multicolumn{1}{c}{ East } \\
\hline Prevalence range of FD & $23-26 \%$ & $12-29 \%$ \\
FD sub-types proportion & EPS 55\% & EPS 30\% \\
& PDS 45\% & PDS 70\% \\
& $10-30 \%$ & $30-70 \%$ \\
Prevalence range of $H$. pylori infection in & & \\
$\quad$ the general population & $5-10 \%$ & $20-30 \%$ \\
$\begin{array}{l}\text { \% symptom improvement with } H . \text { pylori } \\
\text { eradication in FD patients }\end{array}$ & & \\
\hline
\end{tabular}

FD, functional dyspepsia; $H$. pylori, Helicobacter pylori; EPS, epigastric pain syndrome; PDS, post prandial distress syndrome. 
symptom in IBS patients in Asia. ${ }^{18,19}$ This cultural variation in symptom perception was elegantly demonstrated in a multi-center, Indian study using different diagnostic criteria for IBS (MIIBS). Ghoshal et $\mathrm{al}^{20}$ reported that the Manning criteria had the highest sensitivity (91.0\%), followed by the Asian criteria (74.5\%), whilst the Rome I (68.0\%), Rome III (52.5\%) and Rome II (40.0\%) had much lower accuracies. In both the Manning and Asian criteria, "abdominal pain or discomfort" were not included as an absolute requirement for the diagnosis of IBS, which resulted in their greater frequency for diagnosing IBS in the Indian population. ${ }^{8}$ Similar findings have been reported in other Asian populations. In a Hong Kong study, $68.0 \%$ of patients with IBS reported bloating, compared to only $32.0 \%$ who complained of abdominal pain. ${ }^{21}$ In a study from Singapore, $62.0 \%$ of IBS patients complained of abdominal bloating. ${ }^{22}$ In a study of 662 subjects from China, $58.0 \%$ of patients reported abdominal pain compared with $63.0 \%$ with bloating (Table 2). ${ }^{23}$ If the Rome IV criteria is followed, whereby abdominal pain is mandatory, then more Asian patients with IBS will be under-diagnosed. ${ }^{24}$ Table 3 highlights the different symptombased diagnostic criteria for IBS.

Cultural differences have also led to difficulties in sub-typing in Asian IBS patients using the Rome criteria. In a rural communitybased survey of 2774 adults in India, Ghoshal and Singh ${ }^{25}$ reported that a large portion (83.0\%) of IBS subjects were classified as IBSmixed using the Rome criteria, based on its' definition of stool frequency and stool form. However, when the Asian criteria was applied to the same population, only $12.0 \%$ were classified as IBSmixed, with the majority of patients classified as IBS-D. ${ }^{25}$ Similarly, in the Indian urban (MIIBS) community study, Ghoshal et $\mathrm{al}^{20}$ also demonstrated that using the Asian criteria, compared to the Rome III criteria, reduced the mixed-subtype of IBS from $77.6 \%$ to $15.7 \%$. These studies further indicate that cultural perception of symptoms can lead to diagnostic dilemmas in Asian patients with IBS, if only international criteria (eg, Rome criteria) were used.

Table 2. Abdominal Pain and Bloating Frequency in Irritable Bowel Syndrome Population-based Studies: East Versus West

\begin{tabular}{|c|c|c|}
\hline & Abdominal pain & Bloating \\
\hline \multicolumn{3}{|l|}{$\underline{\text { Eastern studies }}$} \\
\hline Hong Kong ${ }^{21}$ & $32 \%$ & $68 \%$ \\
\hline China $^{23}$ & $58 \%$ & $63 \%$ \\
\hline \multicolumn{3}{|l|}{$\underline{\text { Western studies }}$} \\
\hline Europe (multi-center) $)^{56}$ & $88 \%$ & $80 \%$ \\
\hline United States $^{57}$ & $100 \%$ & $83 \%$ \\
\hline
\end{tabular}

\section{Lifestyle and Cultural Habits}

The true prevalence of functional constipation (FC) among most Asian adults is not known. A recent systemic review of randomised clinical trials in China indicated a $\mathrm{FC}$ prevalence of $6 \%{ }^{26}$ Other Asian countries, including Singapore, Taiwan, and Korea have similarly indicated a prevalence from $3-12 \%$ for $\mathrm{FC}^{27-30}$ These Asian data contrasts significantly with a reported 14-19\% prevalence of FC from North America and Europe, based on systemic reviews (Table 4). ${ }^{31,32}$

The difference in prevalence of constipation between the East and the West once again may be due to cultural habits particular to the East. The usual recommended daily dietary fiber intake is 20.0-30.0 g in adults, but the Asian diet traditionally contains a greater amount of fiber than most Western diets. In a recent review article, Rahman et $\mathrm{al}^{8}$ compared the mean daily fiber intake of the average Indian adult at $52.0 \mathrm{~g}$ to only $13.3 \mathrm{~g}$ for the average North American adult. The influence of fiber on intestinal transit is well recognised. Previous experimental work has demonstrated an inverse relationship between dietary fiber and colonic transit time. ${ }^{33}$ Furthermore, more fiber results in a greater stool weight, which additionally reduces colonic transit time. In the light of the differences in dietary fiber intake, Rahman et $\mathrm{al}^{8}$ additionally showed that the mean intestinal transit time among Northern Indian adults was 39.9 hours compared to 83.4 hours in Caucasian adults (Fig. 1).

Another cultural practice unique to Asians, which may be responsible for less constipation, relates to the defecation posture. The squatting position is a common posture for defecation in Asia, particularly in rural areas, whilst most of the Western population defecate on a sitting toilet. The relevance of these defecating positions relates to the recto-anal angle, which is a major factor in the continence of solid rectal content. In a squatting position, the rectoanal canal straightens and converts the rectoanal canal into a straight canal, facilitating rectal emptying. ${ }^{34}$ In a study among healthy volunteers, Sikirov ${ }^{35}$ evaluated time spent for bowel emptying and level of difficulty in defecating between the squatting position and 2 levels of the sitting position. Compared to the standard sitting position, squatting resulted in a shorted mean defecation time ( 0.9 vs 2.1 minutes) and there was less difficulty (subjectively) in defecation with squatting as well. Hence, these 2 cultural factors of diet and defecating positions, may be partially responsible for the lower rate of constipation in Asians compared to Westerners. 
Table 3. Irritable Bowel Syndrome Diagnostic Criteria: East Versus West

\begin{tabular}{|c|c|c|c|c|c|c|}
\hline \multirow{2}{*}{$\begin{array}{c}\text { Diagnostic } \\
\text { criteria }\end{array}$} & \multirow{2}{*}{$\begin{array}{c}\text { East } \\
\text { Asian }(2010)^{18}\end{array}$} & \multicolumn{5}{|c|}{ West } \\
\hline & & Manning $(1978)^{21}$ & Rome I (1989) & Rome II $(1999)^{21}$ & Rome III $(2006)^{21}$ & Rome IV (2016) \\
\hline Duration & At least 3 months & None & $\begin{array}{l}\text { At least } 3 \text { months } \\
\text { of }\end{array}$ & $\begin{array}{l}\text { At least } 12 \text { weeks } \\
\text { in past } 12 \\
\text { months }\end{array}$ & $\begin{array}{l}\text { At least } 3 \text { days per } \\
\text { month in past } 12 \\
\text { weeks }\end{array}$ & $\begin{array}{l}\text { At least } 1 \text { day per } \\
\text { week in the last } 3 \\
\text { months }\end{array}$ \\
\hline $\begin{array}{l}\text { Essential } \\
\text { symptoms }\end{array}$ & $\begin{array}{l}\text { 1. Recurrent abdominal pain, } \\
\text { 2. Bloating or } \\
\text { 3. Other discomfort }\end{array}$ & $\begin{array}{l}2 \text { or more of the } \\
\text { following symp- } \\
\text { toms: } \\
\text { 1.Abdominal dis- } \\
\text { tension } \\
\text { 2. Pain relief with } \\
\text { defecation } \\
\text { 3. Frequent stools } \\
\text { with pain } \\
\text { 4. Looser stools } \\
\text { with pain } \\
\text { 5. Passage of mu- } \\
\text { cus } \\
\text { 6. Sensation of in- } \\
\text { complete evacu- } \\
\text { ation }\end{array}$ & $\begin{array}{l}\text { 1. Continuous } \\
\text { or recurrent } \\
\text { abdominal pain } \\
\text { - relieved with } \\
\text { defecation or } \\
\text { associated with } \\
\text { change in stool } \\
\text { consistency }\end{array}$ & $\begin{array}{l}\text { 1. Continuous or } \\
\text { recurrent ab- } \\
\text { dominal pain or } \\
\text { discomfort }\end{array}$ & $\begin{array}{l}\text { 1. Continuous or } \\
\text { recurrent ab- } \\
\text { dominal pain or } \\
\text { discomfort }\end{array}$ & $\begin{array}{l}\text { 1. Continuous or } \\
\text { recurrent ab- } \\
\text { dominal pain }\end{array}$ \\
\hline $\begin{array}{l}\text { Additional } \\
\text { criteria }\end{array}$ & $\begin{array}{l}\text { With } 1 \text { or more of the } \\
\text { following: } \\
\text { relief with defecation } \\
\text { Change in stool form } \\
\text { Change in stool frequency }\end{array}$ & & $\begin{array}{l}\text { With at least } 2 \text { of } \\
\text { the following on } \\
\text { at least } 25 \% \text { of } \\
\text { days: } \\
\text { 1. Altered stool } \\
\text { frequency } \\
\text { 2. Altered stool } \\
\text { form } \\
\text { 3. Altered stool } \\
\text { passage }\end{array}$ & $\begin{array}{l}\text { With at least } 2 \text { of } \\
\text { the following: } \\
\text { 1. Relief with def- } \\
\text { ecation } \\
\text { 2. Altered stool } \\
\text { frequency } \\
\text { 3. Altered stool } \\
\text { form }\end{array}$ & $\begin{array}{l}\text { With at least } 2 \text { of } \\
\text { the following: } \\
\text { 1. Relief with def- } \\
\text { ecation } \\
\text { 2. Altered stool } \\
\text { frequency } \\
\text { 3. Altered stool } \\
\text { form }\end{array}$ & $\begin{array}{l}\text { Associated with } 2 \\
\text { or more of the } \\
\text { following: } \\
\text { related to defeca- } \\
\text { tion } \\
\text { Associated with a } \\
\text { change in stool } \\
\text { frequency } \\
\text { Associated with a } \\
\text { change in stool } \\
\text { form }\end{array}$ \\
\hline
\end{tabular}

Table 4. Functional Constipation Prevalence in Eastern and Western Populations

\begin{tabular}{lccc}
\hline Countries/Region & $\begin{array}{c}\text { Diagnostic } \\
\text { criteria }\end{array}$ & $\begin{array}{c}\text { Sample } \\
\text { population (n) }\end{array}$ & $\begin{array}{c}\text { Prevalence } \\
\text { of functional } \\
\text { constipation }\end{array}$ \\
\hline$\underline{\text { Eastern }}$ & & & \\
China $^{26}$ & Rome II & 16078 & $6.0 \%$ \\
Taiwan $^{28}$ & Rome II & 2865 & $8.5 \%$ \\
Korea $^{29}$ & Rome II & 1029 & $9.2 \%$ \\
Western $_{\text {Oceania }}{ }^{31}$ & Rome II & 1673 & $30.7 \%$ \\
Europe $^{31}$ & Rome II & 647 & $16.6 \%$ \\
United States $^{32}$ & Rome II & 10018 & $14.7 \%$ \\
Canada $^{32}$ & Rome II & 1149 & $14.9 \%$ \\
\hline
\end{tabular}

\section{Culture and Epidemiological Perspectives of Functional Gastrointestinal Disorders}

Population-based studies in the West have consistently associated dyspepsia among adults with a lower socio-economic status. Socio-demographic factors such as a lower household income, crowded household, low education level, accommodation with no central heating have been associated with dyspepsia in the United Kingdom and North America. ${ }^{36,37}$ However, the situation in Asia appears to be different. Based on the Rome II questionnaire, Mahadeva et $\mathrm{al}^{38,39}$ had previously conducted large $(\mathrm{n}=4000)$ population-based studies in representative communities in both urban and 
rural Malaysia. The survey revealed a greater prevalence of dyspepsia $(24.5 \%)$ among urban adults with a higher socioeconomic status compared to rural adults with a lower socioeconomic background (14.6\%). Similarly, Pan et $\mathrm{al}^{40}$ had conducted a population-based survey among 2486 subjects within Beijing and in a nearby rural community. IBS, based on the Manning criteria, was prevalent in $10.5 \%$ of the urban adults compared to $6.1 \%$ in the rural areas (Table 5).

Whilst urban-rural FGID differences in Asia may be due to environmental and socio-demographic factors, cultural variation between urban and rural communities may have a role as well. With rapid urbanization, dietary patterns have changed markedly in many Asian urban populations. In a recent report on dietary transition in rapidly developing East Asian countries, Kim et al ${ }^{41}$ highlighted the increasing trend in animal food products, including fat intake, associated with economic prosperity. This increase in dietary fat intake is relevant to FD. In a small sample sized study (FD subjects $n=8$, controls $\mathrm{n}=8$ ), Pilichiewicz et $\mathrm{al}^{42}$ had demonstrated that a highfat meal induced more symptoms, especially pain and nausea, than an isocaloric high-carbohydrate meal in FD subjects compared to controls.

Apart from dietary variation, differences in lifestyle and mental health may be responsible for the urban-rural divide in Asian FGID. The link between psychological disorders and FGID is well established. Not only do disorders like anxiety lead to the development of $\mathrm{FD},{ }^{43}$ but a bidirectional pathway between the brain and gut has been indicated. ${ }^{44}$ In the Asian setting, Miwa ${ }^{45}$ was able to demonstrate that Japanese adults with FGID had a higher degree of "stress perception" and "sensitivity to stress", compared to non-FGID controls, in a population-based study. In the large population-based studies of both urban and rural Malaysia, Ma-

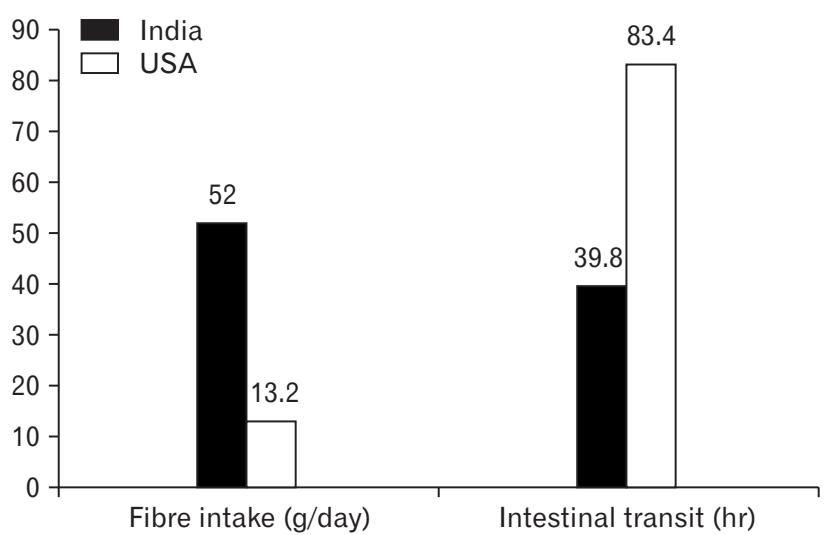

Figure 1. Fiber intake and intestinal transit: East vs West. Adapted from Rahman et al. ${ }^{8}$ hadeva et $\mathrm{al}^{38,39}$ had additionally explored health-related quality of life and anxiety presence in FD subjects. Compared to rural adults with FD, urban FD subjects had a greater amount of anxiety (38.0\% urban vs $8.8 \%$ rural). Furthermore, overall health-related quality of life was significantly lower among urban adults with FD compared to their rural counterparts (Fig. 2). The reason why adults in urban Asia have a greater amount of psychological disorders despite a higher socioeconomic status, compared to the rural population, remains uncertain.

\section{Culture and Healthcare Seeking Behavior -}

Cultural attitudes to health greatly influence healthcare seeking behavior. This is particularly so for FGIDs, which have symptoms which overlap with organic disease such as GI malignancy. In a population-based study from Bangladesh, Masud et $\mathrm{al}^{46}$ and Perveen et $\mathrm{al}^{47}$ reported that urban adults with IBS consulted healthcare facilities significantly more than their rural counterparts (65.5\% urban vs $34.9 \%$ rural). Similarly, two separate studies from India reported that healthcare consultation was greater in urban compared to rural IBS adults ( $28.9 \%$ urban vs $17.2 \%$ rural). ${ }^{8}$ In the Indian studies, most IBS subjects sought treatment for their symptoms from either Indian traditional practitioners (Ayurveda) or from homeopathy experts, with only $18.0 \%$ seeking attention from modern medical practitioners. ${ }^{8}$ These observations suggest a cultural bias towards traditional practitioners rather than modern, Western-trained healthcare practices, in many parts of the Indian sub-continent (Table 5).

For FD, the Malaysian population-based studies demonstrated that rural adults with dyspepsia were more likely to consult primary and secondary care medical facilities compared to urban adults with dyspepsia (Fig. 3). ${ }^{48}$ Additionally, the urban FD subjects tended to self-medicate with over-the-counter medication or herbal/traditional

Table 5. Urban Versus Rural Differences in Prevalence and Healthcare Seeking Behavior in Asian Studies

\begin{tabular}{lrrl}
\hline & Urban & Rural & Country \\
\hline Prevalence & & & \\
$\quad$ Functional dyspepsia & $24.5 \%$ & $14.6 \%$ & $\begin{array}{l}\text { Malaysia } \\
\text { IBS }\end{array}$ \\
Healthcare consultation rate & $10.5 \%$ & $6.1 \%$ & China \\
Functional dyspepsia & $28.7 \%$ & $41.4 \%$ & Malaysia \\
IBS & $28.9 \%$ & $17.2 \%$ & India \\
& $65.5 \%$ & $34.9 \%$ & Bangladesh \\
\hline
\end{tabular}

IBS, irritable bowel syndrome. 
A

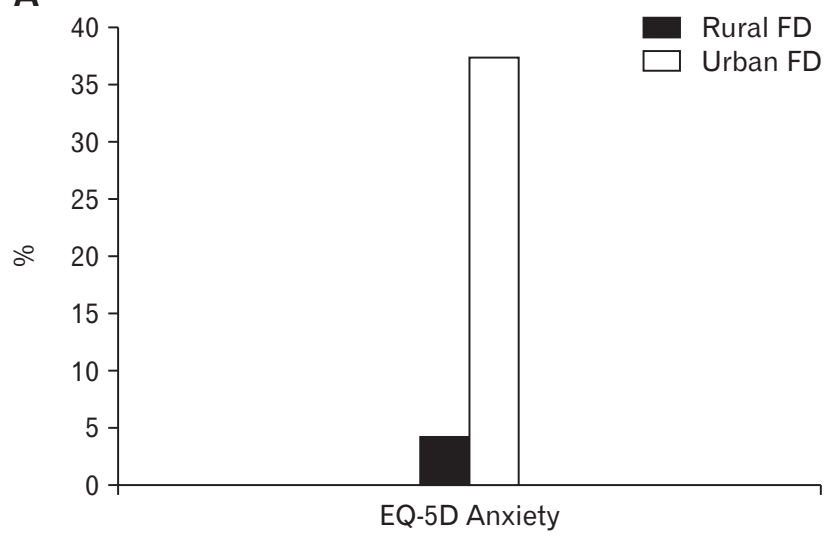

B

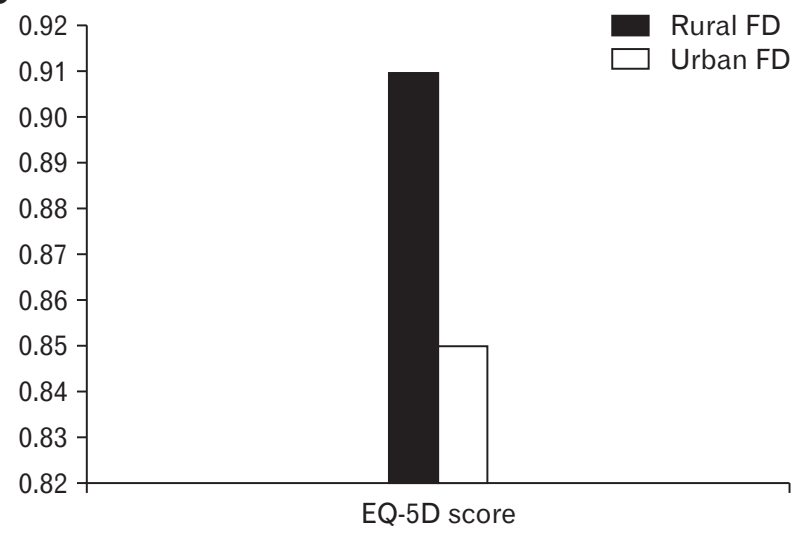

Figure 2. Anxiety (A) and quality of life (B) in Asian functional dyspepsia (FD): rural vs urban. EQ-5D, EuroQol 5 dimensions. Adapted from Mahadeva et al. ${ }^{38,39}$

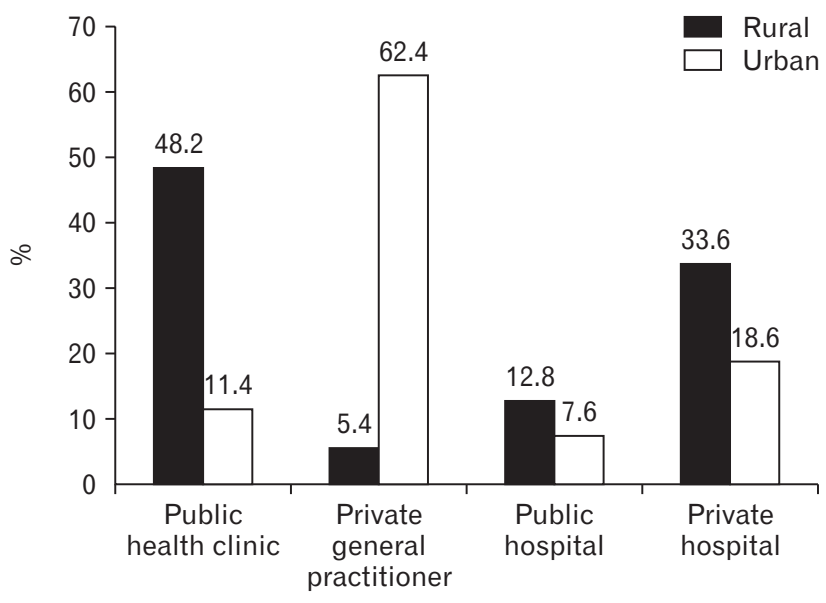

Figure 3. Medical consultation for functional dyspepsia: rural vs urban. Adapted from Mahadeva et al. ${ }^{48}$

remedies more than their rural counterparts. ${ }^{48}$ This healthcare seeking behavior appeared to be the reverse for what was reported for IBS in India and Bangladesh. Although cultural attitudes to health may differ between Malaysians and Indians/Bangladeshis, it is likely that variations in healthcare systems may explain the observation regarding FD in Malaysia. In rural Malaysia, primary healthcare facilities is easily accessible and heavily subsidised. However, in urban Malaysia, primary healthcare is served predominantly by private clinics, which are more expensive and accessibility is limited due to traffic congestion and a poor public transportation system. ${ }^{49}$ Other cultural factors that have been shown to influence healthcare seeking behavior for FGIDs in Asia include psychological co-morbidity. ${ }^{50,51}$ Sleep disturbance, a surrogate marker for psychological co-morbidity, was found to be more prevalent among IBS subjects who consulted healthcare facilities, compared to non-IBS subjects, in a population-based survey in Taiwan. ${ }^{46}$ Anxiety, but not depression, was found to be an independent factor that was associated with healthcare seeking behavior in patients with dyspepsia and IBS in a population-based study from Hong Kong. ${ }^{51}$ Although anxiety is not a cultural factor per se, increased anxiety regarding an organic cause for GI symptoms may be more prevalent among ethnic Chinese, as they are known to have more GI malignancy compared to other ethnic groups in Asia. ${ }^{52,53}$

Cultural factors pertaining to religion have also been suggested to influence healthcare seeking behavior for FGID. In a community-based survey in a predominantly Muslim society in East Malaysia, Lee et al had demonstrated that Muslim females who were married had more psychosocial symptoms together with FD than their male counterparts, but consultation rates were lower. ${ }^{54}$ Similar observations of a lower female healthcare consultation, despite women having a similar prevalence of IBS as men, have been reported in India, Pakistan and Bangladesh, suggesting a suppressed role of female Muslims. ${ }^{8,47,55}$

\section{Conclusion}

This review has highlighted the important role of cultural factors on FGID in the East/Asia. Although FD, IBS and FC have been the main FGID conditions discussed in this review, it is likely that other FGID conditions in Asia may be similarly affected by cultural differences. Language, symptom perception and cultural habits strongly influence disease presentation in the East. Dietary habits additionally influence the epidemiology of FGID in the East. Additionally, changing dietary patterns and variation in psychologi- 
cal morbidity, particularly between urban and rural dwellers have led to unique differences in FGID within similar countries. Lastly, cultural preferences for traditional or local remedies and variation in healthcare systems, lead to a diverse healthcare seeking behavior in Asian patients with FGID. All of these factors are important ultimately to manage FGID more effectively in the East, and to reduce the disease burden to both society and healthcare systems. Nevertheless, socio-demographic and socio-cultural data from many parts of Asia are lacking and more information is still required from this vast continent.

\section{Financial support: None.}

\section{Conflicts of interest: None.}

Author contributions: Kee-Huat Chuah: initial draft of manuscript; and Sanjiv Mahadeva: critical revision and final draft of manuscript.

\section{References}

1. Ford AC, Forman D, Bailey AG, Axon AT, Moayyedi P. Effect of dyspepsia on survival: a longitudinal 10-year follow-up study. Am J Gastroenterol 2012;107:912-921.

2. Chang JY, Locke GR 3rd, McNally MA et al. Impact of functional gastrointestinal disorders on survival in the community. Am J Gastroenterol 2010;105:822-832.

3. Mahadeva S, Yadav H, Everett SM, Goh KL. Economic impact of dyspepsia in rural and urban malaysia: a population-based study. J Neurogastroenterol Motil 2012;18:43-57.

4. Mahadeva S, Ford AC. Clinical and epidemiological differences in functional dyspepsia between the east and the west. Neurogastroenterol Motil 2016;28:167-174.

5. El-Serag HB, Talley NJ. Health-related quality of life in functional dyspepsia. Aliment Pharmacol Ther 2003;18:387-393.

6. Van Oudenhove L, Levy RL, Crowell MD, et al. Biopsychosocial aspects of functional gastrointestinal disorders: how central and environmental processes contribute to the development and expression of functional gastrointestinal disorders. Gastroenterology 2016;150:1355-1367, e2.

7. Francisconi CF, Sperber AD, Fang X, et al. Multicultural aspects in functional gastrointestinal disorders (FGIDs). Gastroenterology 2016;150:1344-1354, e2.

8. Rahman MM, Mahadeva S, Ghoshal UC. Epidemiological and clinical perspectives on irritable bowel syndrome in India, Bangladesh and Malaysia: a review. World J Gastroenterol. 2017;23:6788-6801.

9. Lee JY, Kim N, Kim GH, Kim GH. Comparing the areas of interest in the field of functional gastrointestinal disorder and neurogastroenterology and motility between the east and the west. J Neurogastroenterol
Motil 2015;21:503-510.

10. Drossman DA. Functional gastrointestinal disorders: history, pathophysiology, clinical features, and Rome IV. Gastroenterology 2016;150:12621279, e2.

11. Miwa H, Ghoshal UC, Fock KM, et al. Asian consensus report on functional dyspepsia. J Gastroenterol Hepatol 2012;27:626-641.

12. Fang YJ, Liou JM, Chen CC, et al. Distinct aetiopathogenesis in subgroups of functional dyspepsia according to the Rome III criteria. Gut 2015;64:1517-1528.

13. Ford AC, Bercik P, Morgan DG, Bolino C, Pintos-Sanchez MI, Moayyedi P. The Rome III criteria for the diagnosis of functional dyspepsia in secondary care are not superior to previous definitions. Gastroenterology 2014;146:932-940.

14. Mahadeva S, Raman MC, Ford AC, et al. Gastro-oesophageal reflux is more prevalent in western dyspeptics: a prospective comparison of British and South-East Asian patients with dyspepsia. Aliment Pharmacol Ther 2005;21:1483-1490.

15. Suzuki H, Moayyedi P. Helicobacter pylori infection in functional dyspepsia. Nat Rev Gastroenterol Hepatol 2013;10:168-174.

16. Hooi JKY, Lai WY, Ng WK, et al. Global prevalence of Helicobacter pylori infection: systematic review and meta-analysis. Gastroenterology 2017;153:420-429.

17. Chow TK, Lambert JR, Wahlqvist ML, Hsu-Hage BH. Helicobacter pylori in Melbourne Chinese immigrants: evidence for oral-oral transmission via chopsticks. J Gastroenterol Hepatol 1995;10:562-569.

18. Gwee KA, Bak YT, Ghoshal UC, et al. Asian consensus on irritable bowel syndrome. J Gastroenterol Hepatol 2010;25:1189-1205.

19. Chang FY, Lu CL, Chen TS. The current prevalence of irritable bowel syndrome in Asia. J Neurogastroenterol Motil 2010;16:389-400.

20. Ghoshal UC, Abraham P, Bhatia SJ, et al. Comparison of manning, Rome I, II, and III, and asian diagnostic criteria: report of the multicentric Indian irritable bowel syndrome (MIIBS) study. Indian J Gastroenterol 2013;32:369-375.

21. Kwan AC, Hu WH, Chan YK, Yeung YW, Lai TS, Yuen H. Prevalence of irritable bowel syndrome in Hong Kong. J Gastroenterol Hepatol 2002;17:1180-1186.

22. Gwee KA, Wee S, Wong ML, Png DJ. The prevalence, symptom characteristics, and impact of irritable bowel syndrome in an asian urban community. Am J Gastroenterol 2004;99:924-931.

23. Si JM, Wang LJ, Chen SJ, Sun LM, Dai N. Irritable bowel syndrome consulters in Zhejiang province: the symptoms pattern, predominant bowel habit subgroups and quality of life. World J Gastroenterol 2004;10:1059-1064.

24. Gwee KA, Lu CL, Ghoshal UC. Epidemiology of irritable bowel syndrome in Asia: something old, something new, something borrowed. J Gastroenterol Hepatol 2009;24:1601-1607.

25. Ghoshal UC, Singh R. Frequency and risk factors of functional gastrointestinal disorders in a rural Indian population. J Gastroenterol Hepatol 2017;32:378-387.

26. Zhao YF, Ma XQ, Wang R, et al. Epidemiology of functional constipation and comparison with constipation-predominant irritable bowel syndrome: the systematic investigation of gastrointestinal diseases in China 
(SILC). Aliment Pharmacol Ther 2011;34:1020-1029.

27. Chen GD, Hu SW, Chen YC, Lin TL, Lin LY. Prevalence and correlations of anal incontinence and constipation in Taiwanese women. Neurourol Urodyn 2003;22:664-669.

28. Lu CL, Chang FY, Chen CY, Luo JC, Lee SD. Significance of Rome II-defined functional constipation in Taiwan and comparison with constipation-predominant irritable bowel syndrome. Aliment Pharmacol Ther 2006;24:429-438.

29. Jun DW, Park HY, Lee OY, et al. A population-based study on bowel habits in a Korean community: prevalence of functional constipation and self-reported constipation. Dig Dis Sci 2006;51:1471-1477.

30. Wong ML, Wee S, Pin CH, Gan GL, Ye HC. Sociodemographic and lifestyle factors associated with constipation in an elderly Asian community. Am J Gastroenterol 1999;94:1283-1291.

31. Peppas G, Alexiou VG, Mourtzoukou E, Falagas ME. Epidemiology of constipation in Europe and Oceania: a systematic review. BMC gastroenterol 2008;8:5.

32. Higgins PD, Johanson JF. Epidemiology of constipation in North America: a systematic review. Am J Gastroenterol 2004;99:750-759.

33. Cummings JH. Constipation, dietary fibre and the control of large bowel function. Postgrad Med J 1984;60:811-819.

34. Tagart RE. The anal canal and rectum: their varying relationship and its effect on anal continence. Dis Colon Rectum 1966;9:449-452.

35. Sikirov D. Comparison of straining during defecation in three positions: results and implications for human health. DigDis Sci 2003;48:12011205.

36. Drossman DA, Li Z, Andruzzi E, et al. U.S. householder survey of functional gastrointestinal disorders. Prevalence, sociodemography, and health impact. Dig Dis Sci 1993;38:1569-1580.

37. Moayyedi P, Forman D, Braunholtz D, et al. The proportion of upper gastrointestinal symptoms in the community associated with Helicobacter pylori, lifestyle factors, and nonsteroidal anti-inflammatory drugs. Leeds HELP study group. Am J Gastroenterol 2000;95:1448-1455.

38. Mahadeva S, Yadav H, Rampal S, Everett SM, Goh KL. Ethnic variation, epidemiological factors and quality of life impairment associated with dyspepsia in urban Malaysia. Aliment Pharmacol Ther 2010;31:1141-1151.

39. Mahadeva S, Yadav H, Rampal S, Goh KL. Risk factors associated with dyspepsia in a rural Asian population and its impact on quality of life. Am J Gastroenterol 2010;105:904-912.

40. Pan G, Lu S, Ke M, Han S, Guo H, Fang X. Epidemiologic study of the irritable bowel syndrome in Beijing: stratified randomized study by cluster sampling. Chin Med J 2000;113;35-39.

41. Kim S, Moon S, Popkin BM. The nutrition transition in South Korea. Am J ClinNutr 2000;71:44-53.

42. Pilichiewicz AN, Feltrin KL, Horowitz M, et al. Functional dyspepsia is associated with a greater symptomatic response to fat but not carbohydrate, increased fasting and postprandial CCK, and diminished PYY.
Am J Gastroenterol 2008;103:2613-2623.

43. Aro P, Talley NJ, Johansson SE, Agréus L, Ronkainen J. Anxiety is linked to new-onset dyspepsia in the Swedish population: a 10-year follow-up study. Gastroenterology 2015;148:928-937.

44. Koloski NA, Jones M, Kalantar J, Weltman M, Zaguirre J, Talley NJ. The brain--gut pathway in functional gastrointestinal disorders is bidirectional: a 12-year prospective population-based study. Gut 2012;61:1284-1290.

45. Miwa H. Life style in persons with functional gastrointestinal disorders-large-scale internet survey of lifestyle in Japan. Neurogastroenterol Motil 2012;24:464-471, e217.

46. Masud MA, Hasan M, Khan AK. Irritable bowel syndrome in a rural community in Bangladesh: prevalence, symptoms pattern, and health care seeking behavior. Am J Gastroenterol 2001;96:1547-1552.

47. Perveen I, Hasan M, Masud MA, Bhuiyan MM, Rahman MM. Irritable bowel syndrome in a Bangladeshi urban community: prevalence and health care seeking pattern. Saudi J Gastroenterol 2009;15:239-243.

48. Mahadeva S, Yadav H, Everett SM, Goh KL. Factors influencing dyspepsia-related consultation: differences between a rural and an urban population. Neurogastroenterol Motil 2011;23:846-853.

49. Ghani SN, Yadav H. Health care in Malaysia. Kuala Lumpur: University of Malaya Press 2008:293.

50. Lu CL, Chang FY, Lang HC, Chen CY, Luo JC, Lee SD. Gender difference on the symptoms, health-seeking behaviour, social impact and sleep quality in irritable bowel syndrome: a Rome II-based survey in an apparent healthy adult Chinese population in Taiwan. Aliment Pharmacol Ther 2005;21:1497-1505.

51. Hu WH, Wong WM, Lam CL, et al. Anxiety but not depression determines health care-seeking behaviour in Chinese patients with dyspepsia and irritable bowel syndrome: a population-based study. Aliment Pharmacol Ther 2002;16:2081-2088.

52. Goh KL, Quek KF, Yeo GT, et al. Colorectal cancer in Asians: a demographic and anatomic survey in Malaysian patients undergoing colonoscopy. Aliment Pharmacol Ther 2005;22:859-864.

53. Goh KL, Cheah PL, Md N, Quek KF, Parasakthi N. Ethnicity and H. pylori as risk factors for gastric cancer in Malaysia: a prospective case control study. Am J Gastroenterol 2007;102:40-45.

54. Lee YY, Chua AS. What indigestion means to the malays? J Neurogastroenterol Motil 2013;19:295-300.

55. Abid S, Siddiqui S, Jafri W. Discriminant value of Rome III questionnaire in dyspeptic patients. Saudi J Gastroenterol 2011;17:129-133.

56. Hungin AP, Whorwell PJ, Tack J, Mearin F. The prevalence, patterns and impact of irritable bowel syndrome: an international survey of 40,000 subjects. Aliment Pharmacol Ther 2003;17:643-650.

57. Ringel Y, Williams RE, Kalilani L, Cook SF. Prevalence, characteristics, and impact of bloating symptoms in patients with irritable bowel syndrome. Clin Gastroenterol Hepatol 2009;7:68-72. 